\title{
Sistema de Parques em Vargem Grande
}

Vargem Grande Park System

Sistema de Parques en Vargem Grande

Victória Ferreira Robadey Carvalho Arquiteta e Urbanista, Apoio Técnico TCT4 - FAPERJ, UFRJ, Brasil. victoriafrobadey@gmail.com

Bruna Peres Battemarco Engenheira Civil, Mestranda em Engenharia civil, UFRJ, Brasil. brunabattemarco@poli.ufrj.br

Andrea Queiroz Rego Professora Doutora, UFRJ, Brasil. andrea.queiroz@ufrj.br

Aline Pires Veról

Professor Doutora, UFRJ, Brasil. alineverol@fau.ufrj.br 


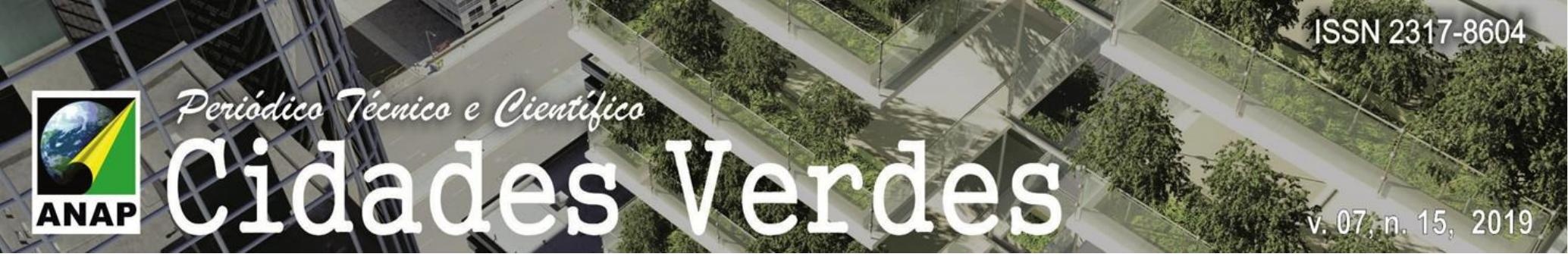

\title{
RESUMO
}

O sistema de parques de Vargem Grande, na zona oeste do município do Rio de Janeiro, tem como objetivo a criação de um espaço livre público para os moradores do bairro de Vargem Grande, conjugando ações que visem a mitigação das cheias locais, protegendo ambientalmente o ecossistema. O sistema proposto é composto por quatro parques: Parque Cascalho, Parque Bonito, Parque Sernambetiba e o Parque Linear, um corredor verde que conecta os três parques anteriores. O programa dos parques é composto por praças com mobiliário infantil, academia ao ar livre, áreas com espreguiçadeiras, mesas e cadeiras para refeições, rampas de skate e mobiliário para atividades com cães. As praças projetadas possuem características multifuncionais, com atividades de baixo impacto ambiental, respeitando as leis ambientais vigentes. Nesse sentido, foram propostas bacias de retenção em cada parque, conjugando sua função de drenagem com o paisagismo. A metodologia empregada considerou a análise do lugar e o reconhecimento da paisagem, seguida pelo levantamento das legislações vigentes na região, caracterização do uso do solo e hidrografia; levantamento dos espaços livres públicos do bairro; proposta de desenho urbano do parque com base na mancha de alagamento atual; proposição de bacias de retenção com seu pré-dimensionamento. Os resultados finais indicam a contribuição para a mitigação de cheias na região, permitindo a urbanidade da área, a partir da criação de espaços de lazer de uso público.

PALAVRAS-CHAVE: Paisagem, Sistema de Espaços livres, Drenagem Urbana Sustentável.

\begin{abstract}
The Vargem Grande Park System, in the west zone of the city of Rio de Janeiro aims to create a public open space for residents of the Vargem Grande neighborhood, combining actions to mitigate local floods, protecting the environment ecosystem. The proposed system consists of four parks: Cascalho Park, Bonito Park, Sernambetiba Park and Linear Park, a green corridor that connects the three previous parks. The park program consists of squares with children's furniture, outdoor gym, lounge areas, dining tables, skate ramps, and dog activity furniture. The designed squares have multifunctional characteristics, with activities of low environment impact, respecting the current environmental laws. In this sense, retention basins were proposed in each park, combining its drainage function with landscaping. The employed methodology considered the analysis of the place and the recognition of the landscape, followed by the survey of the current legislation in the region, characterization of the land use and hydrography; survey of public open spaces in the neighborhood; proposition of the park urban design based on the current floodplain; and the proposition of retention basins with a pre-dimensioning. The final results indicate the contribution to flood mitigation in the region, allowing the urbanity of the area through the creation of leisure spaces for public use.
\end{abstract}

KEYWORDS: Landscape, Open Space Systems, Sustainable Urban Drainage.

\section{RESUMEN}

El Sistema de Parques Vargem Grande en el oeste de la ciudad de Río de Janeiro tiene como objetivo crear un espacio público y gratuito para los residentes del vecindario Vargem Grande, combinando acciones destinadas a mitigar las inundaciones locales, proteger el medio ambiente ecossistema. El sistema propuesto consta de cuatro parques: Parque Cascalho, Parque Bonito, Parque Sernambetiba y Parque Linear, un corredor verde que conecta los tres parques anteriores. El programa del parque consiste en plazas con muebles para niños, gimnasio al aire libre, áreas de tumbonas, mesas y sillas de comedor, rampas de patinaje y muebles para actividades para perros. Los cuadrados diseñados tienen características multifuncionales, con actividades de bajo impacto ambiental, respetando las leyes ambientales vigentes. En este sentido, se propusieron cuencas de retención en cada parque, combinando su función de drenaje con paisajismo. La metodología empleada consideró el análisis del lugar y el reconocimiento del paisaje, seguido del estudio de la legislación vigente en la región, la caracterización del uso del suelo y la hidrografía; encuesta de espacios públicos libres en el barrio; diseño urbano propuesto del parque basado en la llanura de inundación actual; propuesta de cuenca de retención con su pre-dimensionamiento. Los resultados finales indican la contribución a la mitigación de inundaciones en la región, permitiendo la urbanidad del área a través de la creación de espacios de ocio para uso público.

PALABRAS CLAVE: Paisaje, Sistema de Espacios Libres, Drenaje Urbano Sostenible. 


\section{INTRODUÇÃO}

O Sistema de Espaços Livres de edificações é constituído por espaços livres urbanos que apresentam relação de conectividade e complementaridade, mesmo que não tenham sido planejados ou implantados como tal (MACEDO et al., 2007). Os espaços livres geralmente estão relacionados ao meio em que estão localizados, e se definem por acessibilidade, uso, se são públicos ou privados, minerais ou vegetais, tendo funções como recreação, convívio e circulação. Os espaços livres estão ligados diretamente com outros sistemas urbanos, que podem se sobrepor ou justapor enquanto sistema de ações. De acordo com Tângari et al. (2013), o Sistema de Espaços Livres de edificações pode ser visto como um método de entendimento dos padrões de tipológicos dos tecidos urbanos, tendo este conceito servido como base para entender melhor como se constitui um espaço livre público.

O segundo conceito para a estruturação deste trabalho é o de ecogênese, defendida pelo paisagista Fernando Chacel. Trata-se de uma ação antrópica, parte integrante de uma paisagem cultural que utiliza, para recuperação dos seus componentes bióticos, associações e indivíduos próprios que compõem os ecossistemas originais. Ainda, segundo Chacel, as áreas degradadas são recuperadas por meio da criação de parques em um trabalho multidisciplinar. Curado (2007) ressalta que o desenho de Chacel é simples e modesto, com forte destaque, em suas paisagens, para a própria natureza. Em seu livro Paisagismo e Ecogênese (CHACEL, 2001), Chacel descreve os casos de estruturação de parques na zona oeste da cidade do Rio de Janeiro, mostrando como a vegetação cria espaços de lazer e convivências dentro dos parques públicos.

De forma complementar aos conceitos apresentados, cabe destacar o uso de paisagens multifuncionais, que vem ganhando destaque nas discussões técnicas e científicas, principalmente quando envolvem o manejo sustentável de águas pluviais em áreas urbanas sob uma ótica mais sistêmica. De acordo com Miguez et al. (2015), a ideia básica da utilização de paisagens multifuncionais é que uma área pode cumprir diferentes objetivos e funções quanto a interesses ecológicos, econômicos, culturais, históricos, sociais e estéticos. Os mesmos autores indicam que reservatórios em lotes, praças, parques ou ao longo dos rios, medidas de infiltração como pavimentos permeáveis, ações de reflorestamento e manutenção de áreas verdes, entre outras, são opções para a materialização desses objetivos, podendo ainda integrar o ambiente urbano harmoniosamente, configurando áreas de lazer em tempo seco.

Dentre os reservatórios de armazenamento de águas pluviais, destacam-se as bacias de retenção, projetadas para reter o escoamento superficial de cheias urbanas, em um lago permanente. Neste tipo de reservatório, o escoamento superficial de cada evento chuvoso é detido e tratado por meio da sedimentação dos sólidos em suspensão e dos mecanismos de decomposição biológica nos intervalos entre os eventos de precipitação (CGSD, 2000), além de evitar a ressuspensão dos sedimentos depositados. Nas bacias de retenção, o objetivo primário é o do tratamento da água, porém há um efeito secundário, que é o da reservação da água da chuva, em volume disponível acima do nível do lago permanente, para o controle quantitativo das cheias urbanas (AMEC, 2001).

As bacias de retenção, devido a sua multifuncionalidade, têm, como principal finalidade, a redução da carga de contaminante do escoamento, mas também contribuem para a redução do 


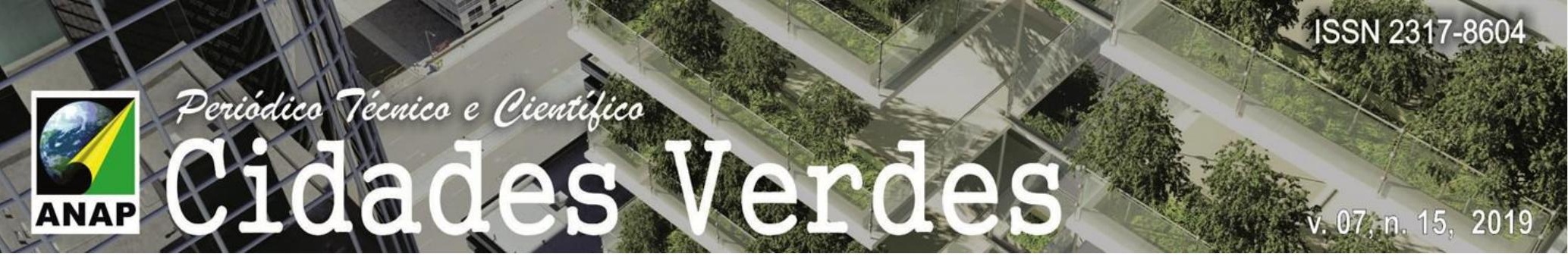

pico do escoamento, o controle da erosão, a melhoria da paisagem (criando espaço recreativo e de lazer), o recarregamento dos aquíferos, etc (LIMA et al., 2006). Bacias de retenção podem ser previstas para criar ambientes saudáveis e funcionais, favorecendo a conservação de espécies de vegetais e animais, assim como adicionando aspectos estéticos que ajudam a elevar a valorização da terra (HALL e POTERFIELD, 2001). De acordo com Miguez et al. (2015), o dimensionamento e a implantação de uma bacia de retenção requerem o conhecimento da topografia e rede hidrográfica, do regime de precipitação, do tipo de solo, do tipo de ocupação da bacia de drenagem, do sistema de drenagem existente, do plano de desenvolvimento e das condições do meio receptor de jusante. A área de drenagem deve ser tal que uma adequada vazão de base seja mantida na bacia.

\section{OBJETIVOS}

Este trabalho tem como objetivo propor o projeto de um parque natural em uma área ambientalmente sensível no Rio de Janeiro, considerando os conceitos de sistemas de espaços livres de edificações, ecogênese e de manejo sustentável de águas pluviais, resgatando as características naturais e garantindo a vitalidade da bacia hidrográfica, bem como permitindo a urbanidade da área, a partir da criação de espaços de lazer de uso público.

\section{METODOLOGIA}

O método empregado considerou as seguintes etapas:

1) Definição da problemática e delimitação do objeto de intervenção;

2) Análise do lugar, reconhecendo sua formação e transformações da paisagem;

3) Levantamento da legislação, morfologia, uso do solo e sistema viário;

4) Caracterização hidrográfica;

5) Levantamento dos espaços livres de valor ambiental dentro do sistema de espaços livres da cidade;

6) Proposta de desenho urbano dos parques considerando a mancha de alagamento atual e usando bacias de retenção para amortecimento das cheias locais;

7) Pré-dimensionamento das bacias de retenção;

Foram feitas visitas de campo, desenvolvimento de mapas e bases cartográficas em Photoshop, Corel Draw e Autocad 2D, bem como fotomontagens representando cenas urbanas projetadas. 


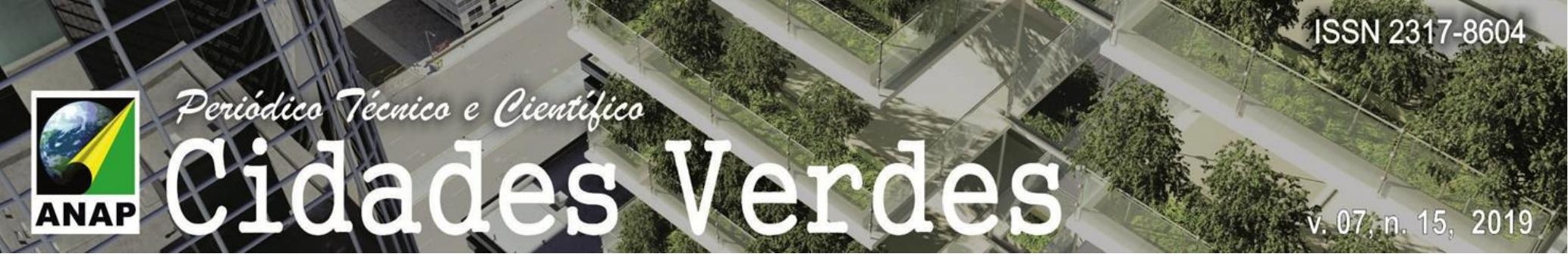

\section{ESTUDO DE CASO}

Vargem Grande é um bairro de grande fragilidade ambiental, localizado na região litorânea oeste da cidade do Rio de Janeiro, em uma extensa planície sedimentar de depósitos recentes do período quaternário, circundado nas laterais pelos Maciço da Pedra Branca e da Tijuca e apresentando expressivo complexo lagunar. Segundo Montezuma et al. (2014), esta é uma região de planícies paludiais, com fragmentos de brejos e remanescentes de mata paludosa esparsa. Ainda segundo os mesmos autores, o solo da região é úmido, com predomínio de turfas (ibid).

A hidrografia da região é parte da Bacia de Jacarepaguá, que se distribui por toda a planície e desemboca no oceano. Nas áreas de planície, a hidrografia segue como rios e riachos que, em geral, têm seus leitos estreitos e de pequenas dimensões, submetendo-se às lagoas próximas Lagoa de Marapendi e a Lagoinha, na Reserva Chico Mendes. O canal mais importante da área é o Canal de Sernambetiba, o principal leito de deságue para o mar da região (TARDIN, 2008). Com ocupação predominantemente agrícola até a década de 1970, a região possui ainda muitos lotes vazios. De acordo com o Plano Diretor de Lúcio Costa, em 1969, esta área deveria permanecer disponível para a implantação de espaços públicos que respeitassem suas peculiaridades ambientais. Atualmente, a ocupação da região tem características bem distintas: ocupação mais densa ao norte, próximo à Vargem Pequena, com condomínios fechados uni e multifamiliares, e poucos espaços livres de uso públicos. Montezuma et al. (2014) descrevem a ocupação da região como:

"(...) baixa densidade de edificações, ocupação marcada por sítios e chácaras em processo crescente de substituição por condomínios horizontais fechados, em geral de dois pavimentos (...), poucos edifícios com um máximo de quatro andares (...), baixa arborização e vegetação presente nas propriedades privadas. Ocupação concentrada ao longo do eixo do rio principal (rio Morto) com rede de sistema de drenagem artesanal presente em todo o terreno."

Segundo Brito et al (2017), está em curso, nessa área, um processo de ocupação irregular, com moradias precárias sem o apoio de infraestrutura urbana adequada, estabelecidas nas margens de rios e canais, provocando danos àquele ambiente e a seus ecossistemas.

O objeto de estudo está localizado no setor G, em uma área delimitada entre a Avenida das Américas, a Estrada Vereador Alceu de Carvalho e a Estrada dos Bandeirantes com baixa densidade ocupacional e com predomínio de condomínios fechados com até 6 pavimentos. Existe pequeno comércio local situado próximo às vias de maior acesso, como a Avenida das Américas e Estrada dos Bandeirantes. A Figura 1 apresenta a localização do recorte de trabalho. 


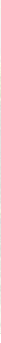

Figura 1 - Localização do recorte de trabalho, em Vargem Grande, nas proximidades do Parque Estadual da Pedra Branca, Praia da Macumba, e da Reserva Natural de Chico Mendes

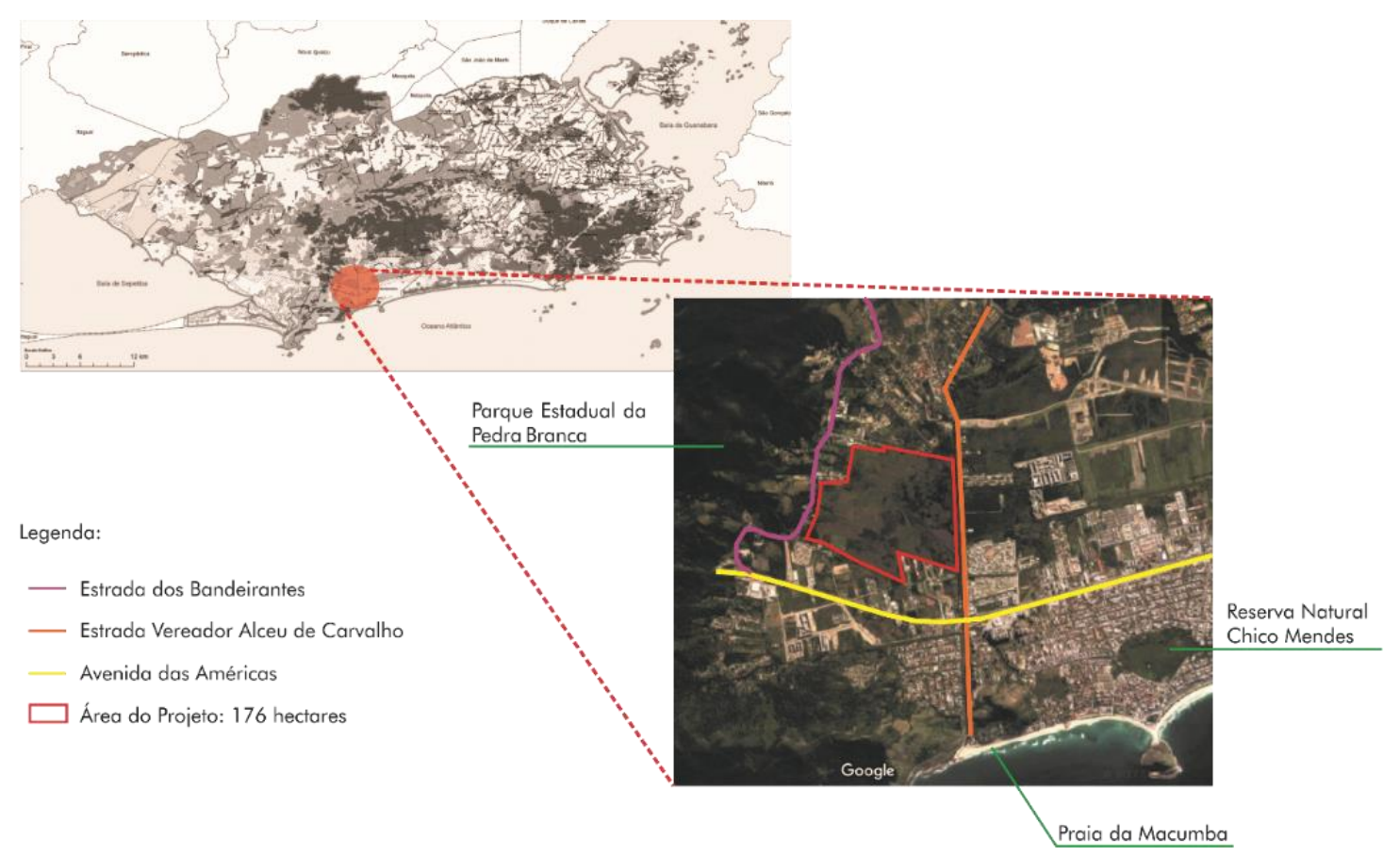

Fonte: VICTORIA ROBADEY, 2017.

Essa região, devido a suas características geográficas, está abaixo do nível do mar, por isso há uma tendência a sofrer alagamentos. Esses alagamentos se concentram próximos às vias, à Estrada Vereador Alceu de Carvalho e à Avenida das Américas e próximo aos canais da região, como o Canal de Sernambetiba. Na figura 2 pode-se observar a concentração das manchas de alagamento na área central-norte de Vargem Grande. 


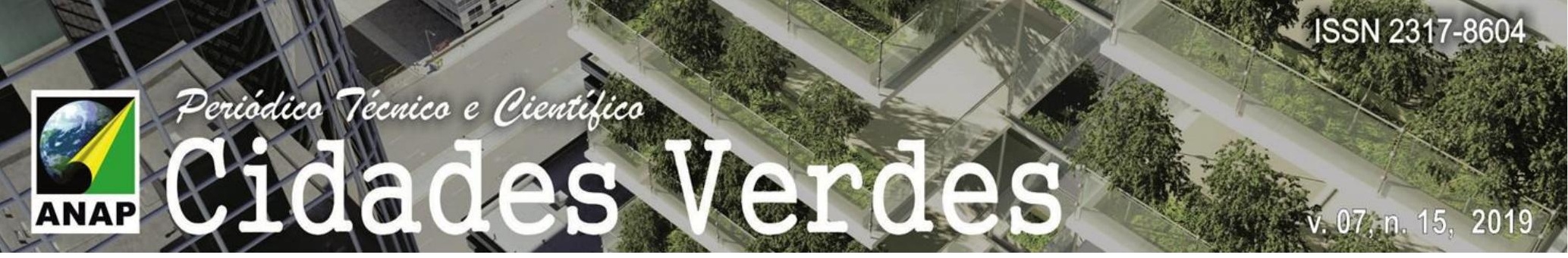

Figura 2 - Mancha de alagamento para a situação atual em Vargem Grande

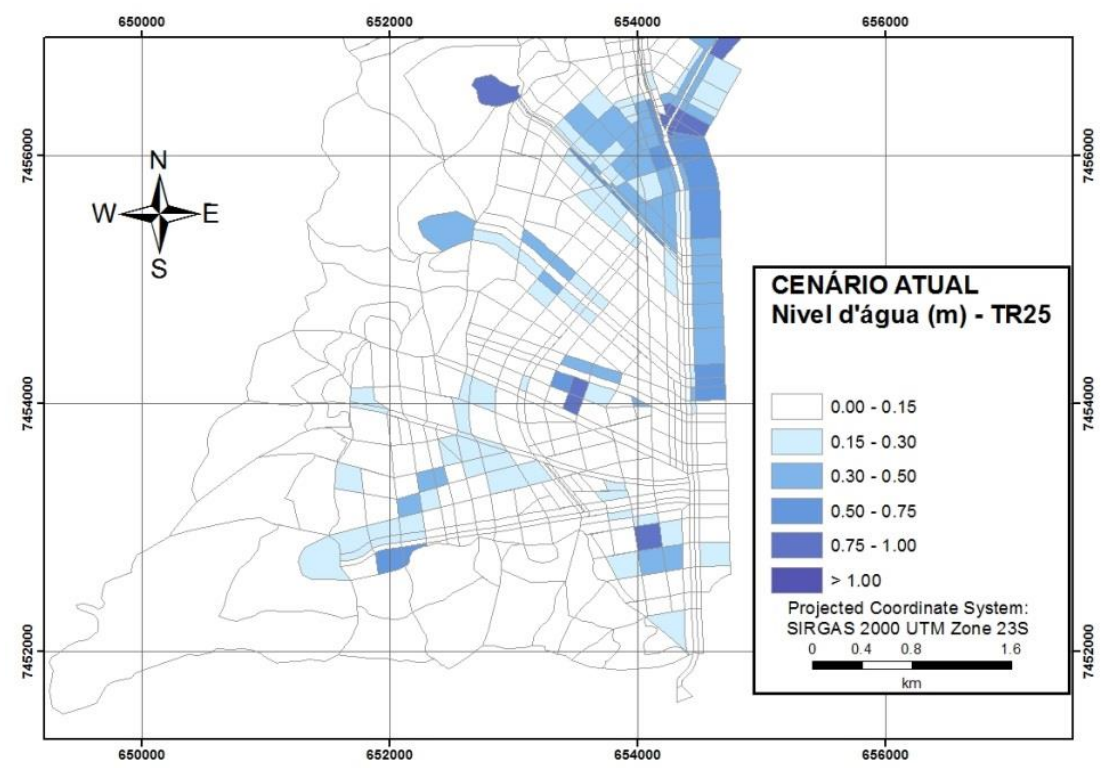

Fonte: MIGUEZ et al, 2019.

Segundo a mancha de alagamento apresentada pela Figura 2, a área mais afetada pelas inundações é a região próxima às confluências dos rios Vargem Grande, Morto e Cascalho, quando ocorrem lâminas maiores que $0,30 \mathrm{~m}$. A observação deste resultado corrobora as informações obtidas in loco a respeito do ponto crítico de alagamento - entre as ruas Joaquim Gomes e Vereador Alceu de Carvalho e a Estrada do Rio Morto (Miguez et al., 2019). A área correspondente ao recorte de estudo também é, de maneira geral, atingida por lâminas maiores de 0,30 , sobretudo próximo aos canais existentes.

O projeto desenvolvido propõe um sistema de parques na área em foco, aliado à criação de um sistema de espaços livres capaz de conectar as áreas de grande relevância ambiental que estão no entorno. Isso se desenvolve, principalmente, através de corredores verdes que, por meio de uma gestão integrada, suprem questões ambientais, sociais, econômicas e culturais. A configuração desse conjunto de soluções está detalhada no próximo item.

\section{RESULTADOS E DISCUSSÕES: O PROJETO DO PARQUE NATURAL}

O Parque Natural foi proposto como sendo um sistema composto por quatro pequenos parques, denominados Parque Cascalho, Parque Bonito, Parque Sernambetiba e Parque Linear, com área total de 64 hectares (Figura 3). O projeto teve como objetivo conectar o espaço livre existente ao entorno, criando assim uma relação entre os espaços livres e o espaço ocupado, respeitando a faixa marginal de proteção de $30 \mathrm{~m}$ de largura dos canais mais importantes da região, como prevê o Código Florestal (BRASIL, 2012).

O Parque Cascalho, localizado mais ao norte da área de estudo, possui o mesmo nome do Rio que o corta e conta com uma área total de 23,61 hectares. O parque localizado mais ao centro da região é o Parque Bonito, que também possui o mesmo nome do Rio que o corta, e conta 


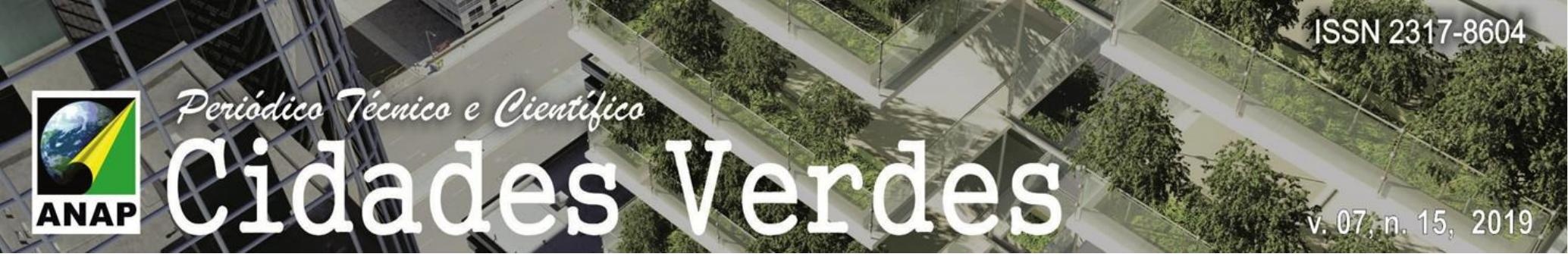

com uma área total de 25,79 hectares. O parque mais ao sul é o Parque Sernambetiba, com uma área total de 22,63 hectares, e é cortado pelo Dreno K, que deságua no canal de Sernambetiba. O Parque Linear, por sua vez, com uma área total de 10,33 hectares, atravessa todo o conjunto de parques ao longo da Estrada Vereador Alceu de Carvalho, ligando-a ao caminho utilizado atualmente para acessar a Reserva Natural Chico Mendes. Neste parque linear, há uma via para carros e, em separado dentro de um corredor verde, há uma ciclovia e mobiliário de apoio para os diferentes setores projetados.

Figura 3 - Planta geral dos espaços livres e da rede hidrográfica da região em estudo

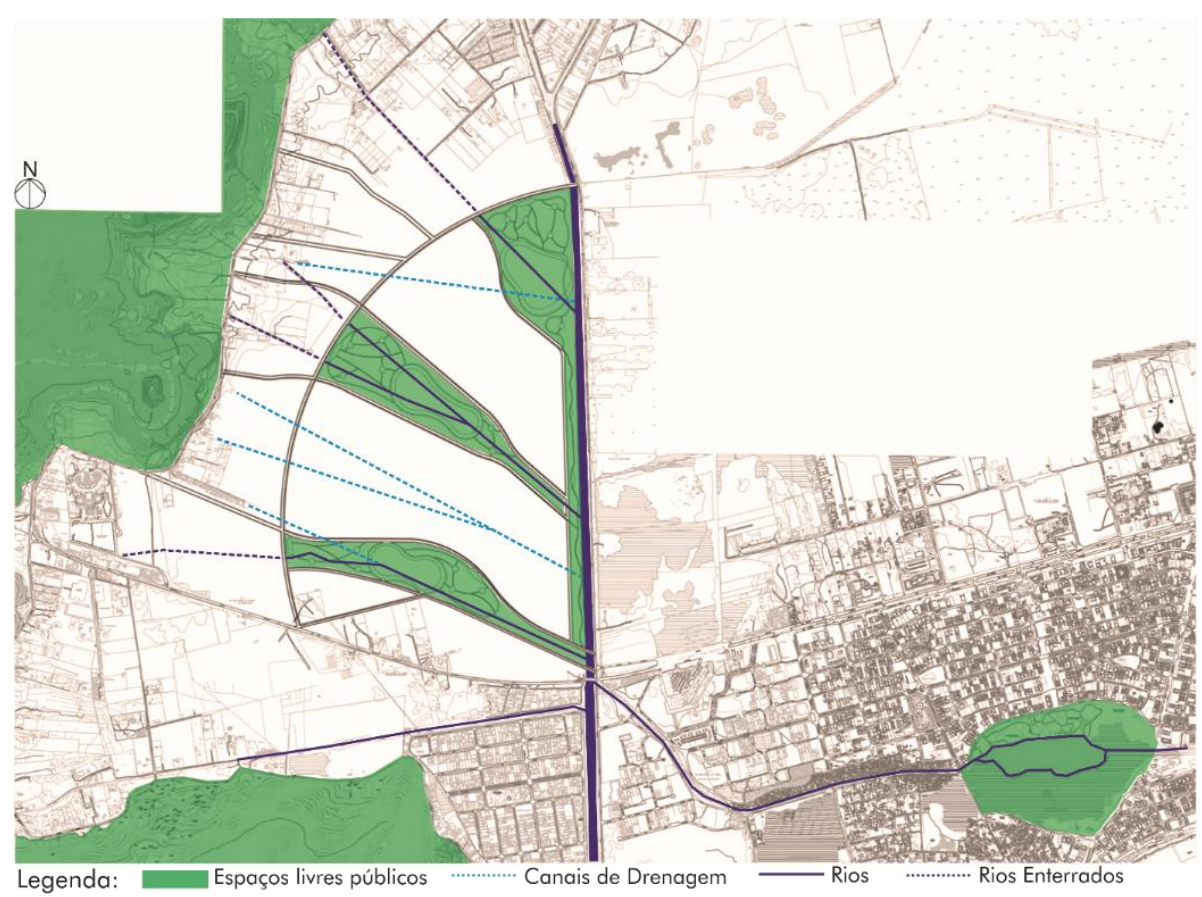

Fonte: VICTORIA ROBADEY, 2017.

O acesso ao parque será feito por algumas vias previstas pelo PEU das Vargens; em complemento, o projeto também prevê vias que seguem o curso dos rios e que permitirão aos pedestres e ciclistas acesso às praças previstas em cada parque, bem como novas vias para a delimitação da área dos parques. Em todas as vias propostas, foram previstas ciclovias, interligadas, para facilitar o deslocamento dos ciclistas entre os parques e para conectá-los ao seu entorno. 


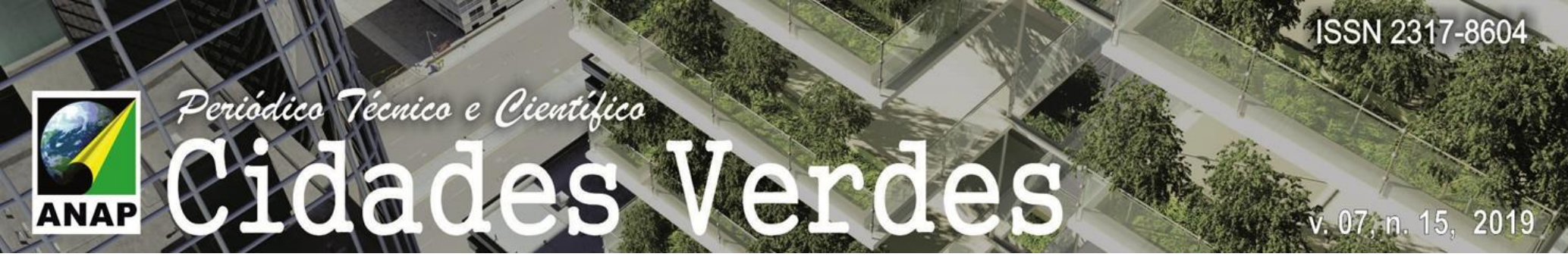

Figura 4 - Acesso ao Parque

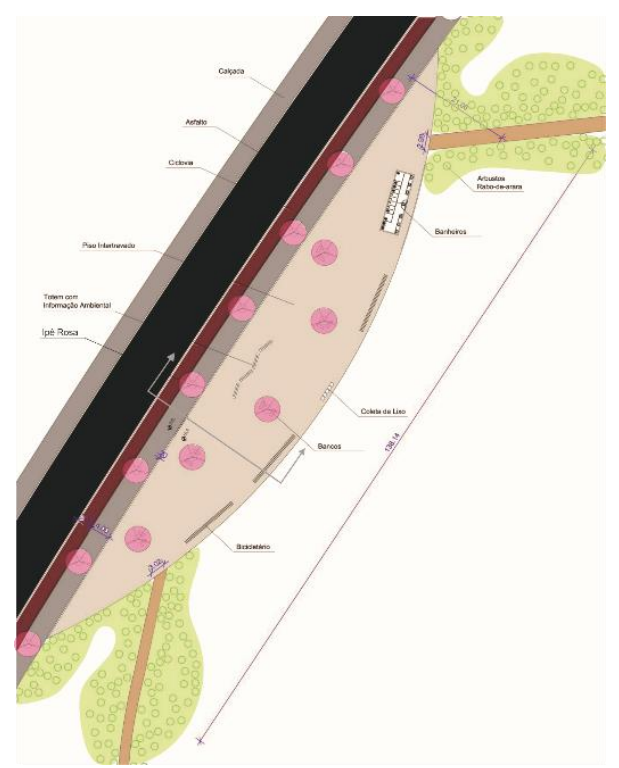

Fonte: VICTORIA ROBADEY, 2017.

Seu programa de necessidades é formado por atividades para o lazer infantil, mobiliário para a terceira idade, área destinada à ginástica, áreas com mesas e cadeiras para refeições e pequenas churrasqueiras e uma área destinada à leitura e ao relaxamento, com espreguiçadeiras e redes. O projeto do parque conta, ainda, com uma área para estacionamento de carros, bicicletários, áreas para os animais.

Figura 5 - Praças com mobiliário infantil e academia ao ar livre
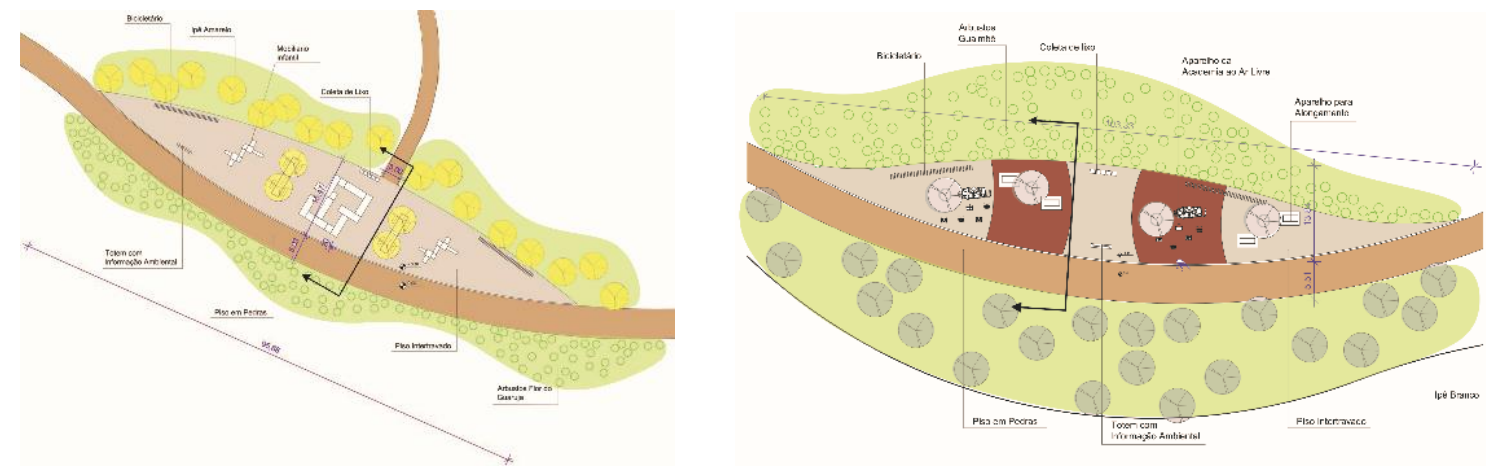

Fonte: VICTORIA ROBADEY, 2017. 


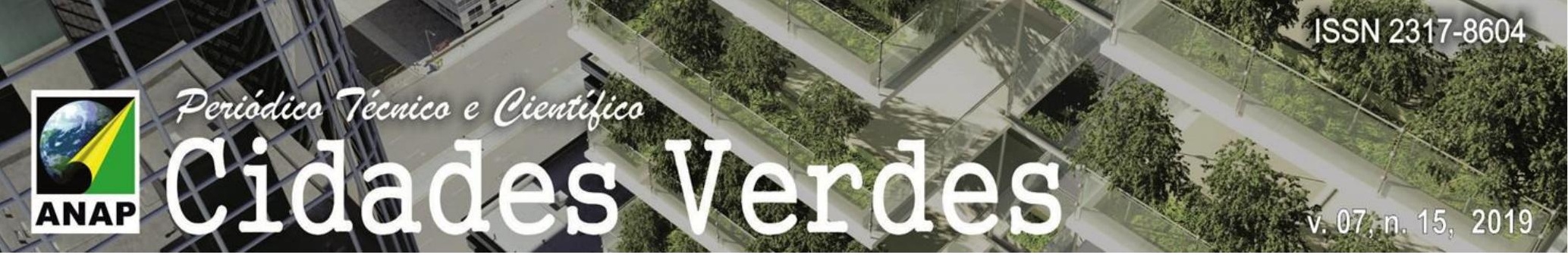

Figura 6 - Praças com mesa, cadeiras e churrasqueiras e com espreguiçadeiras e redes.
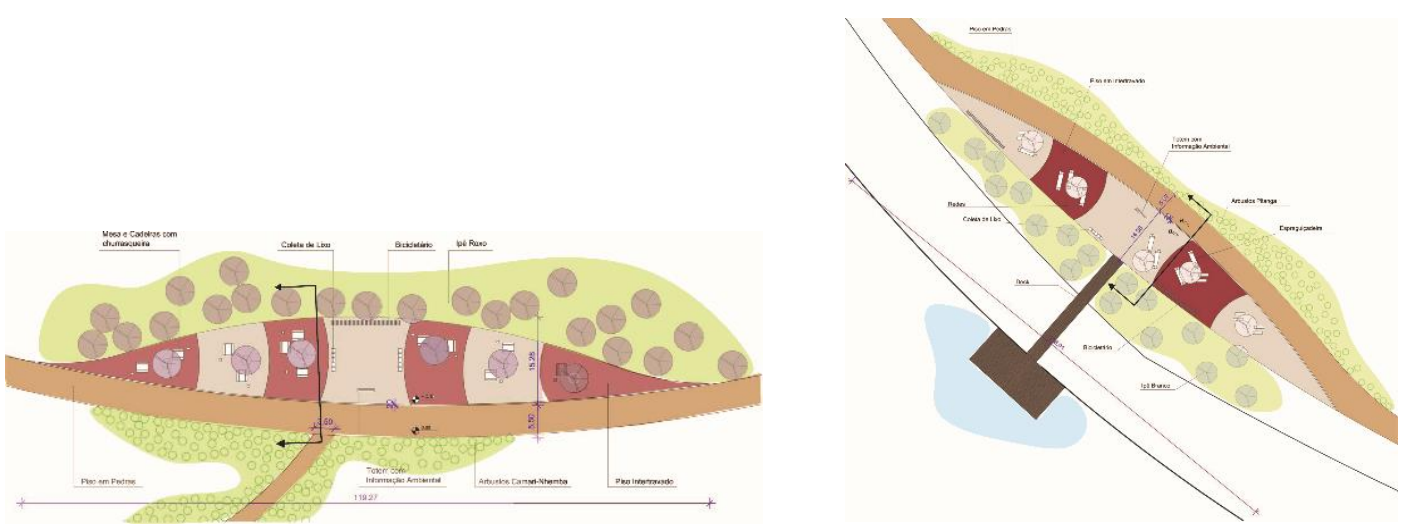

Fonte: VICTORIA ROBADEY,2017.

Figura 7 - Praças com mobiliário para cachorros e mobiliário para skate
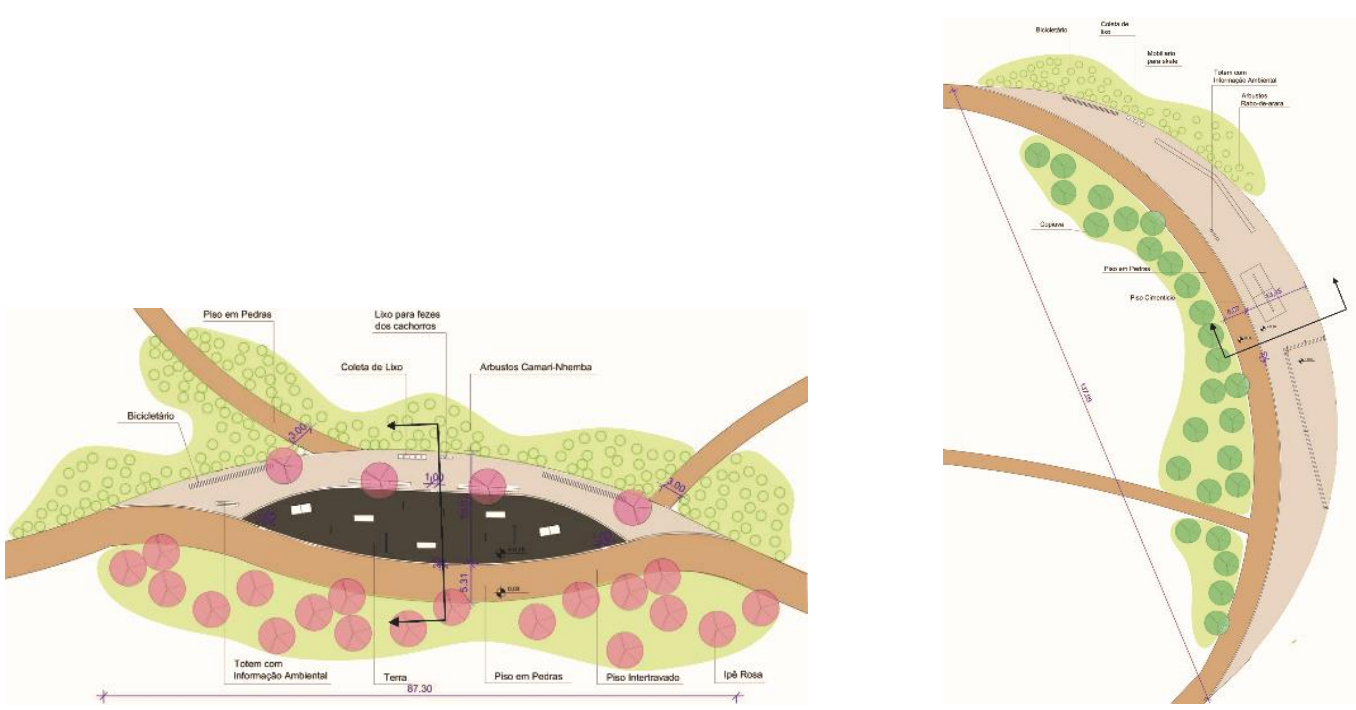

Fonte: VICTORIA ROBADEY, 2017.

As espécies foram estudadas e selecionadas a partir do livro Paisagem e Ecogênese (Chacel, 2001). A planta de Plantio está apresentada na figura 8 e as espécies utilizadas estão apresentadas na Tabela 1. Propôs-se, inicialmente,demarcar com vários tipos de árvores as vias do PEU, corredores verdes e as entradas dos parques. Em seguida, criou-se uma barreira verde com arbustos, demarcando o limite entre os parques e as vias, evitando, assim, o uso de grades. Os arbustos propostos também tinham como objetivo camuflar as trilhas dentro dos parques. Próximo a todas as praças, há árvores, para criarem um sombreamento. Próximo aos lagos e aos riospropôs-se o uso de espécies de manguezal como o mangue preto, branco e vermelho, criando, assim, uma transição entre as espécies de manguezal e as da restinga. 


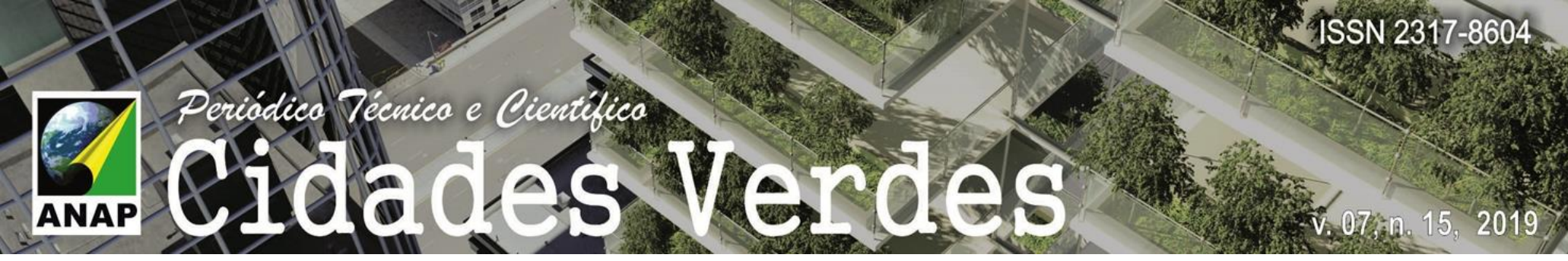

Figura 9 - Sistema de Parques de Vargem Grande - Concepção

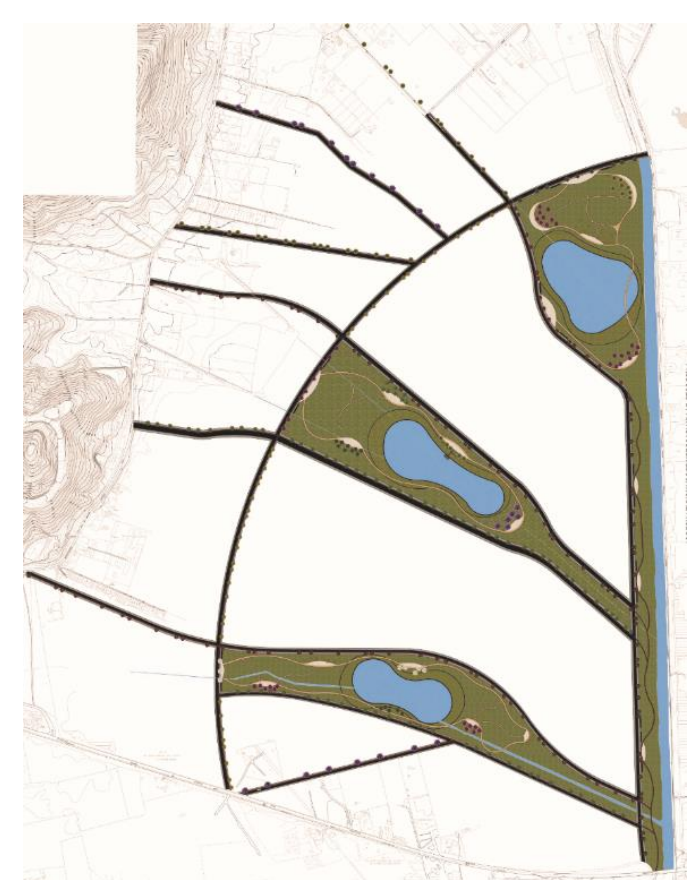

Fonte: VICTORIA ROBADEY, 2017.

Tabela 2: Dimensionamento da Bacia de Retenção - Parque Cascalho

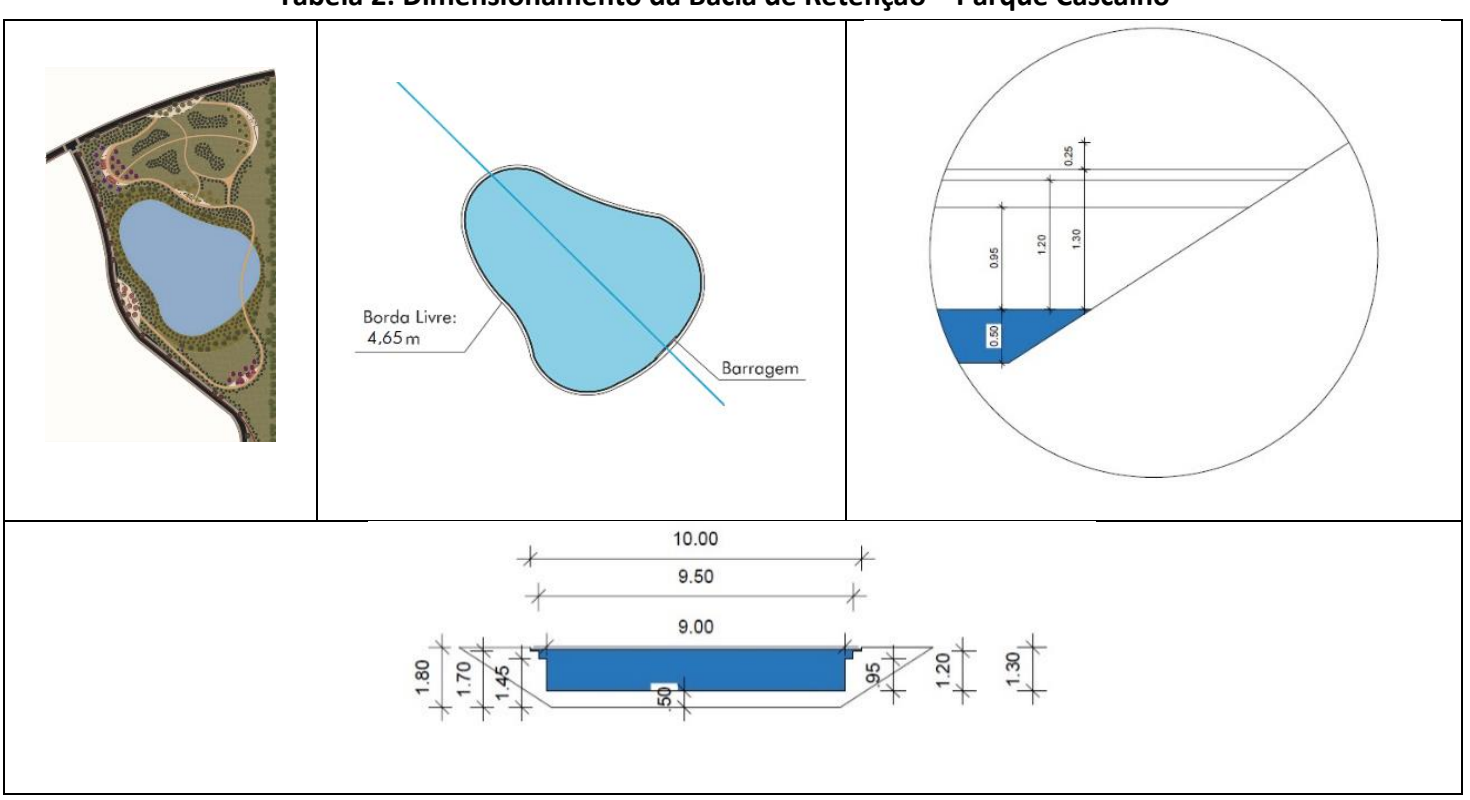


Tabela 3:Dimensionamento da Bacia de Retenção - Parque Bonito

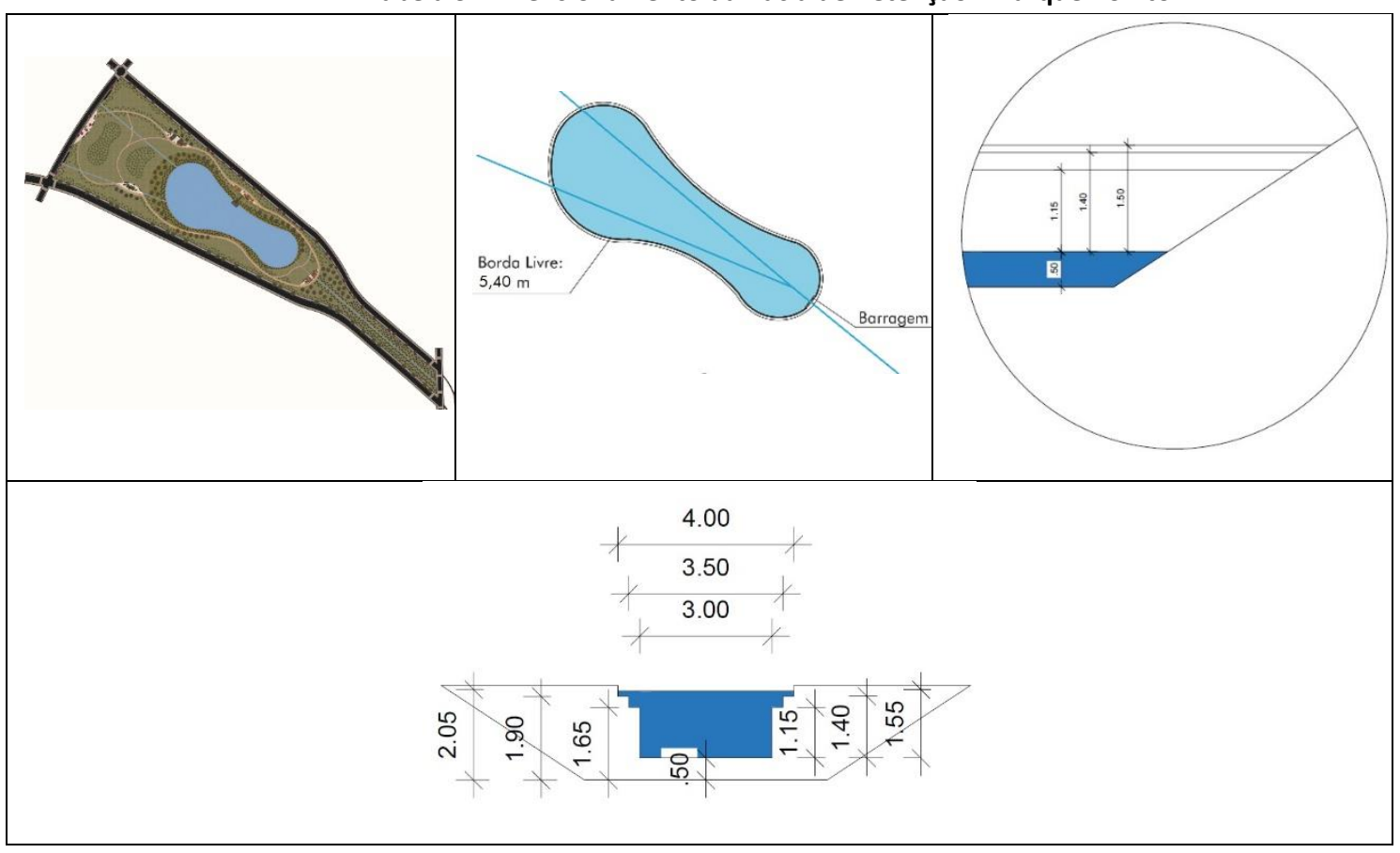

Tabela 4: Dimensionamento da bacia de retenção - Parque Sernambetiba

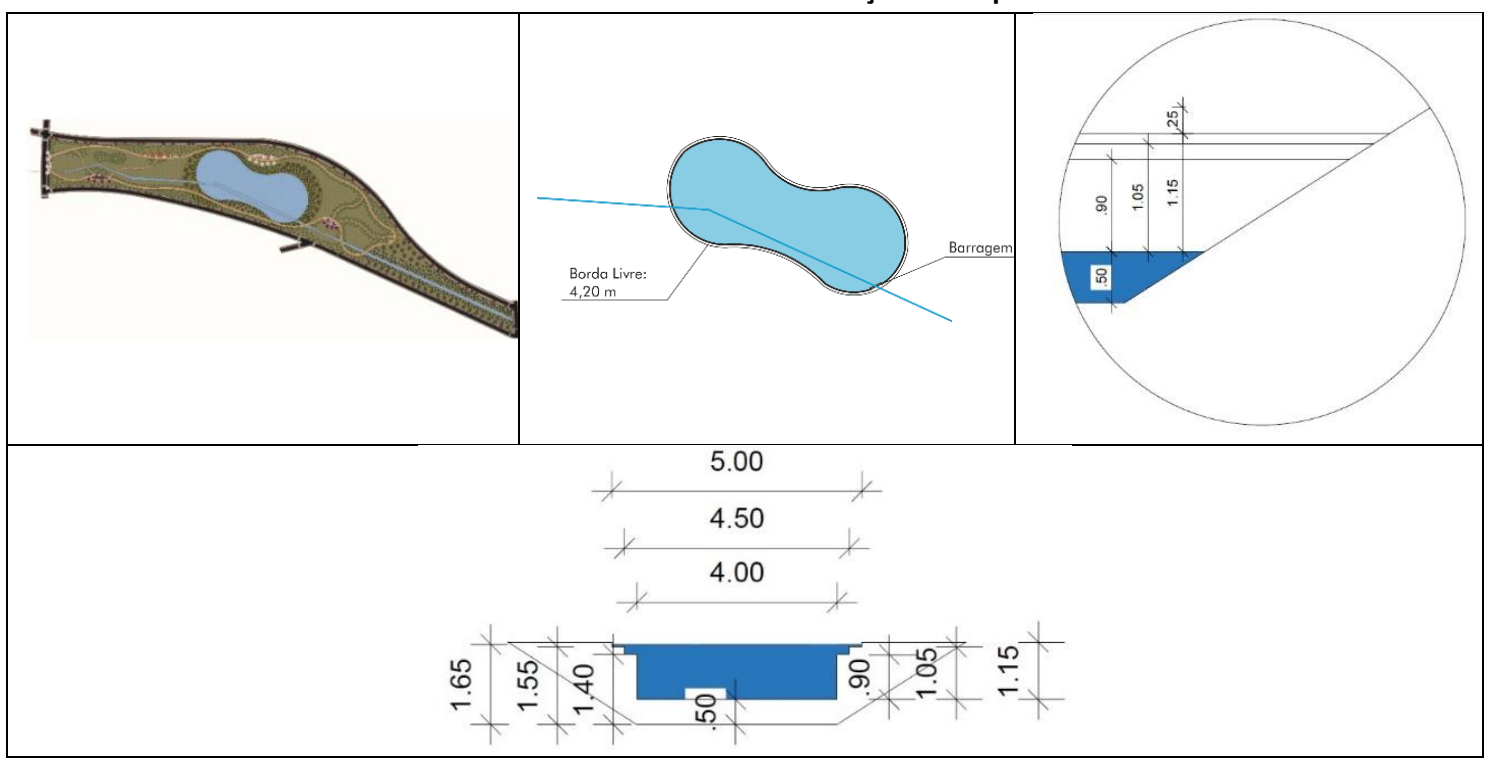

\section{CONCLUSÃO}

A proposta de um parque natural em uma área ambientalmente sensível, como Vargem Grande, no município do Rio de Janeiro, integrando os conceitos de sistemas de espaços livres de edificações, ecogênese e manejo sustentável de águas pluviais, teve como objetivo garantir as características naturais locais, bem como a vitalidade da bacia hidrográfica na qual está inserido. 
